\title{
Renal tubular dysfunction in patients with molecular defects of the insulin receptor gene
}

\author{
Yuki Abe • Toru Watanabe
}

Received: 15 August 2013 / Accepted: 19 August 2013 / Published online: 28 August 2013

(C) Springer-Verlag Berlin Heidelberg 2013

To the editor,

We read with interest on a case of Donohue syndrome with renal tubular dysfunction (RTD) and a mutation in the insulin receptor gene (INSR) written by Hovnik et al. that was published recently in your journal [3]. The authors showed that although recombinant human insulin-like growth factor I (rh-IGF-I) therapy improved RTD, it did not improve the anabolic status of their patient.

We recently reported on a case of Rabson-Mendenhall syndrome with INSR mutations and RTD [1]. Although the patient underwent rh-IGF-I therapy at the age of 4 months, his physical constitution continued to deteriorate, and RTD did not resolve.

The therapeutic effect of rh-IGF-I varies between cases. We suggest that rh-IGF-I may have had an inadequate effect in the patient of the study of Hovnik et al. because anabolic status did not improve.

Chin et al. showed that activation of phosphatidylinositol3-kinase (PI3K) stimulated endocytosis of the renal outer medullary potassium channel (ROMK) [2]. Insulin and IGFI can activate PI $3 \mathrm{~K}$ and therefore may inhibit renal potassium excretion by reducing the abundance of ROMK. However, our patient showed sustained RTD after administration of rhIGF-I, probably due to a poor response to rh-IGF-I. The patient in the study of Hovnik et al. appeared to be in a similar situation to our patient, because rh-IGF-I therapy did not improve their anabolic status. Therefore, recovery of RTD in their patient could not be fully explained by the effect of rhIGF-I.

In our patient, RTD resolved spontaneously at the age of 18 months. The recovery of renal tubular function in Hovnik's patient may have depended partially on rh-IGF-I treatment, although this may not have been the only mechanism. Some renal pathways other than the system mediated by IGF-I develop during infancy and may play a specific role in renal tubular function in patients with insulin receptor insufficiency.

\section{References}

1. Abe Y, Sato T, Takagi M, Watanabe T, Nagayama Y, Hasegawa T, Abe $\mathrm{T}$ (2012) A case of Rabson-Mendenhall syndrome with a novel mutation in the tyrosine kinase domain of the insulin receptor gene complicated by medullary sponge kidney. J Pediatr Endocrinol Metab 25:587-590

2. Cheng CJ, Huang CL (2011) Activation of PI3-kinase stimulates endocytosis of ROMK via Akt1/SGK1-dependent phosphorylation of WNK1. J Am Soc Nephrol 22:460-471

3. Hovnik T, Bratanič N, Podkrajšek KT, Kovač J, Paro D, Podnar T, Bratina N, Battelino T (2013) Severe progressive obstructive cardiomyopathy and renal tubular dysfunction in Donohue syndrome with decreased insulin receptor autophosphorylation due to a novel INSR mutation. Eur J Pediatr 172:1125-1129

\footnotetext{
Y. Abe $(\bowtie) \cdot$ T. Watanabe

Department of Pediatrics, Niigata City General Hospital,

463-7 Shumoku, Chuo-ku, Niigata 950-1197, Japan

e-mail: y-abe@hosp.niigata.niigata.jp
} 